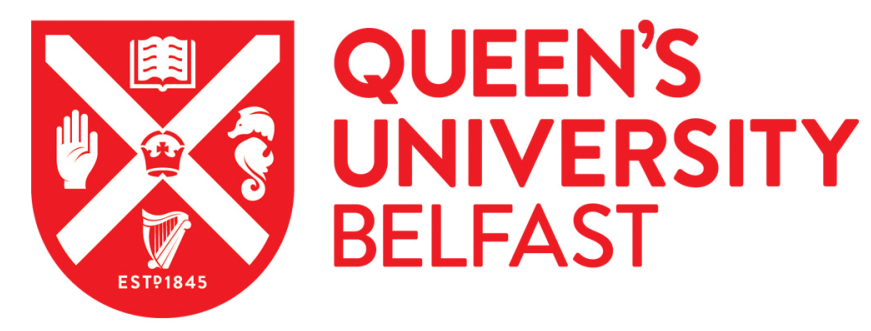

\title{
Players' performance in cross generational game playing
}

Awad, M., \& Craig, C. (2017). Players' performance in cross generational game playing. In Serious Games -3rd Joint International Conference, JCSG 2017, Proceedings (Vol. 10622 , pp. 170-182). (Lecture Notes in Computer Science (including subseries Lecture Notes in Artificial Intelligence and Lecture Notes in Bioinformatics); Vol. 10622 LNCS). Springer Verlag. https://doi.org/10.1007/978-3-319-70111-0_16

Published in:

Serious Games -3rd Joint International Conference, JCSG 2017, Proceedings

Document Version:

Peer reviewed version

Queen's University Belfast - Research Portal:

Link to publication record in Queen's University Belfast Research Portal

Publisher rights

(C) 2017 Springer

This work is made available online in accordance with the publisher's policies. Please refer to any applicable terms of use of the publisher.

\section{General rights}

Copyright for the publications made accessible via the Queen's University Belfast Research Portal is retained by the author(s) and / or other copyright owners and it is a condition of accessing these publications that users recognise and abide by the legal requirements associated with these rights.

Take down policy

The Research Portal is Queen's institutional repository that provides access to Queen's research output. Every effort has been made to ensure that content in the Research Portal does not infringe any person's rights, or applicable UK laws. If you discover content in the Research Portal that you believe breaches copyright or violates any law, please contact openaccess@qub.ac.uk. 


\title{
Players' Performance in Cross Generational Game Playing
}

\author{
Mahmoud Awad ${ }^{1}$, Cathy Craig ${ }^{2}$ \\ ${ }^{1}$ School of Computing, Electronics and Mathematics, Coventry University, Coventry, UK \\ ${ }^{2}$ School of Psychology, Queen's University of Belfast, Belfast, UK
}

\begin{abstract}
This study investigates how the player performance can be analyzed when playing exergames. This analysis aims to enable people with different physical capabilities to play against each other and have fair opportunities to win, contrary to the current implementations of exergames where the winner usually is the player who has better performance (e.g. faster response speed). By implementing this technique into exergames, an older adult will be able to play against a younger one and win.
\end{abstract}

Keywords: cross generation, games for elderly, exergames, player performance

Acknowledgements. This work was supported by Microsoft Research through its PhD Scholarship Program.

\section{$1 \quad$ Introduction}

As the population ages in many countries, it is expected that the number of senior citizens will increase dramatically [1]. It has been well documented how an older adult suffers from age related impairments which can make it difficult for them to be involved in social activities. Not having the appropriate level of action capability can limit the extent of social opportunities that older adults can share with the others. This in turn may further compounds the loneliness they may feel. Recent research however, has suggested that computer games may offer a new way of engaging older adults in both social and physical activities and may in turn positively impact on the emotional well-being of senior citizens [2].

Computer games are a way of socializing across family generations, with grandparents for example using game playing activity to engage in a common activity and share the experience with their grandchildren [3]. Computer games can enhance communication, interaction, and relationships between children and parents, and also between patients and doctors [4]. Older adults play games as an entertaining activity to compete with their children or grandchildren [5], as they are interested in having the opportunity to spend more time with their grandchildren [6]. Kinect and Wii mote games are a very good way of facilitating social interaction between family members. However using body movements as a means of control can add an additional layer of complexity on the way these games are played. This is because players will move 
more muscles and perform higher rate of physical activity. In such games, it is usually the players who can move better and faster who wins the game, which instantly creates a barrier to engagement and competitiveness for people with lesser physical capabilities. Fitness games are not always fun, because they sometimes create an unbalanced challenge when a player falls far behind another skilled player and is not able to compete any more [7]. Individuals will increasingly engage in physical activities if they are reliant not only on their self-efficacy, but are also supported by collective efficacy [8]. If movement based games are embraced as a normal social activity, then using these games will become part of an individual's daily life. However, the community will not embrace these activities if a significant portion of its population is neglected; therefore, including older adults to be an active part of this activity is important to transform movement-based games to be a normal activity in social communities. Giving the older adults full control will increase their immersion in the game; such activities will help older adults to feel better about their physical capabilities because they recognize that they can achieve something. As a result, this will encourage older adults to play and move more often. Playing against a younger adult will make the rehabilitation process not only more enjoyable, but also a social activity where older adults can play with their grandchildren, friends or even with clinicians in the clinic as players are more engaged when they are familiar with their opponent [9].

In this study we were interested in how to design cross generation movement based games for older adults to encourage them to move and exercise so they can stay healthy. For an older adult to be able to use such games they need to be engaged with the game by making the game as much fun for them as possible but also by providing them with meaningful play [10].

\section{$2 \quad$ Related Studies}

Studies show that video games can engage parents and children together in game play. Engaging both old and young people in computer games can benefit both parties [11]. There are some studies that dealt specifically with intergeneration game playing with family members. The study in [5] reported on the design process and the design rationale of a movement based mini-game. The game was designed so that it could be played by senior and younger players together. In this study no difference in the performance of old and young players were found. The study argues that designing for enactive interaction results in ease of use. Enactive interaction is a term coined by Bruner (1964) and is based on the stored knowledge by the motor system of the user in the form of motor responses [12]. This will help seniors who lack experience with computers to play games because they do not need to learn how to memorize complex mappings between the in-game actions and the buttons, instead they can use their experience from life to perform actions and gestures. An example of an enactive interface is swinging the arm to play a table tennis video game. The results of their study indicate that enactive interfaces can be used to help senior players to respond and perform gestures in the game. Similarly, study in[13] shows that designers should consider using familiar mental models that older people developed from past experi- 
ence so that the tools and the information presented relates to past knowledge. Another study in [14] developed a mobile phone application in order to facilitate social support for exercise. The application allowed the users to share their daily steps count with friends and family members, the study was conducted with a group of five women who wanted to increase their physical activity levels. The results indicate that the group who shared their activities with friends were more likely to reach their goals. Based on this, there is evidence that sharing physical activities with others increases engagement and the attainment of the desired goals. To encourage gameplay within family generations, the study in [15] developed an intergenerational family entertainment system called Age Invader that focuses on physical and social interaction. They created a physical game space arena using a mixed reality floor system. Their objective was to facilitate interaction between family members that have different skill levels in using technology. In their findings older adults could precisely understand the game and had better game experience due to the physical nature of the gaming system. In addition, older adults who usually express concern about computers enjoyed playing in an interactive system. The effort level of all players in the game was set according to their physical capabilities; this ensured that all players were challenged appropriately resulting in the game being enjoyed by two different family generations who would not normally play together. The study in [16] presented a prototype game called Curball to be played between an older person and a child. The aim of this study was to design an enjoyable collaborative game for two different generations. However, it focused on game design elements such as how to roll the ball, how to design the levels, and how to make the game easy to learn. It also explored how to make the game playable by using handicaps to control the difficulty of moving the ball. Also in [17] an intergenerational case study was conducted to explore intergenerational game design where children and the elderly play together. The study reported on the design implications for intergenerational games. Findings indicated that the rules of the game are deeply related to the social interaction and that the game rules should encourage cooperation.

The golf handicap system ensures that players of all abilities compete on a level playing field; handicaps in golf allow a golfer's score to be calculated based on the golfer's best previous performance. The player has to post at least 20 scores to get an accurate handicap index. Every two weeks the local golf association updates the handicaps and issues a new handicap index for each player. This index is based on the player's performance on the golf courses; with golf courses having a set of tables based on the slope rating from each of the tees. To calculate a Handicap in Golf the course rating is first of all subtracted from the gross score. The result is multiplied by 113 and divided by the slope rating. Then the lowest 10 of the last 20 differentials are averaged and multiplied by 0.96 . The result is the handicap index [18].

\section{Design Concept}

Research showed that social interaction is one of the main motivations for players to play computer games and that who play for social interaction are competitive players 
[19, 20, 21]. Exergames can provide family members with a social activity that requires active participation. For older players to be part of this activity they must be competitive players. Older adults have a strong desire to play with their grandchildren, and reciprocally grandchildren enjoy playing with their grandparents [17]. To improve the social interaction the game rules must be designed so that they encourage maximum participation among players. A game that is designed for cross generation play should have balancing teams by requiring different skill sets to bridge the divide between teams [5]. Designing an exergame, which takes into account the different physical capabilities players, can enhance their presence to allow them to play against each other. This means that the system is, by definition, inclusive. However, it should also be noted that this system not only allows players with different physical capabilities to play the game, but also allows them to play against each other using fairer game based rules. Some systems, which are designed for diverse users, will respond differently based on each user's need. If two users with different physical capabilities used such a system at the same time, the system will respond to them differently, which would create an unbalanced environment and may lead to two different experiences. To make a movement-based gaming system inclusive and playable by both younger and older adults at the same time the game should respond the same way to both players and give each player a fair representation of his/her performance. This can be realised by measuring the skills of each player separately without comparing them to each other. In this case the game should compare the same player's current performance to his/her best and average performance within the same gaming session. For example, a game may require two players to perform a "run in place" action; the player who runs faster achieves more points. This will mean that the player with superior physical capabilities will always win. In order to maintain the controlling and challenge factors for both players, we should measure the performance of each one separately; so that the player who keeps running at a rate close to his/her best performance will be the winner.

The suggested system should allow people with different physical abilities to play, compete, and have a fair chance of winning. Each player's performance is measured according to his/her best performance. The system compares the current actions to the previous ones and decides how close this action is as a percentage to the best action $(100 \%)$. The player who performs more actions that are close to his/her best will be more likely to win the game.

\section{System Description}

The game that was designed to test this model is a table tennis game. This game was chosen because it does not involve complex movements that cannot be easily performed by older adults, the game rules are clear and easy to understand and it also offers an enactive interface that most players are familiar with. We used the MS Kinect sensor as the input device to detect player movements. We used the Kinect's full body skeleton tracking, as it gives relatively good results for tracking the hands, in $\mathrm{XYZ}$ coordinates, which can in turn be used efficiently in a gaming context. 


\section{Calculating performance}

The table tennis game requires interceptive actions that are similar to the real action used to play table tennis in the real world. However, in the real table tennis game information about where and when to intercept the ball, including extra information about hand adjustments needed to steer the racket to its final position, are also very important [22]. In this virtual game the extra information is not required as there are no rackets held in the hands or the players or tracked by the Kinect, instead hand position is used to control the position of a virtual racket. This reduction in information should make the virtual game easier to play. The only action that is required from the player is to decide when and where to intercept the ball and the speed with which they need to swing their hand. However, extra information can be added to the virtual game such as the trajectory of the hand before and after it intercepts the virtual ball.

It is important to decide how performance will be measured. In this case we tracked the player's hand movements and also recorded the velocity and range of motion in $\mathrm{x}, \mathrm{y}$ and $\mathrm{z}$ axes. Other metrics that can be measured are angular velocity and response time. Each of the three axes are measured separately, which gives a better approximation of performance for different game contexts. These calculations are performed per drawing frame with a frame corresponding to 0.008 seconds, however the Kinect sampling framerate is $30 \mathrm{~Hz}$ at maximum which will update the Kinect data once every 0.033 second.

Velocity in each axis is the change in distance in meters that the hand moves between successive frames, while the range of motion is the value in each axis relative to maximum and minimum values that the hand could reach. To find the current performance we used the following equation:

$$
\mathrm{P}=\mathrm{W}_{1} \cdot \mathrm{P}_{\text {velocity }}+\mathrm{W}_{2} \cdot \mathrm{P}_{\text {range }}
$$

Where:

- P: current performance

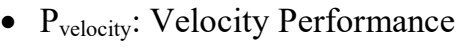

- Prange: Range Performance

- $\mathrm{W}_{1}$ and $\mathrm{W}_{2}$ : weight values that are taken from a predefined table, where $\mathrm{W}_{1}+\mathrm{W}_{2}=$ 1. Their purpose is to weight which is more important Velocity or Range in different game contexts.

To calculate velocity and range performance the following Pythagorean equations were used:

$$
\begin{aligned}
& \mathrm{P}_{\text {velocity }}=\sqrt{V x^{2}+V y^{2}+V z^{2}} \\
& \mathrm{P}_{\text {range }}=\sqrt{R x^{2}+R y^{2}+R z^{2}}
\end{aligned}
$$




\section{Best Hit Algorithm}

After calculating the $\mathrm{P}$ value in each frame, a simple algorithm we called Best Hit is used to keep track of the current performance relative to the best action, with Fig.2 illustrating the steps in this algorithm, When the player hits the ball with a velocity greater than the maximum, the ball will be reflected with the highest power. The first hit will be always set as the initial value as best performance with any other successive hits with greater values being set as a new best performance value and will launch the maximum power.

\section{$7 \quad$ System Implementation}

Fig.1 shows a screenshot of the game, the screen is split into two parts, so each player can see his/her own perspective of the table. Players control the racket by either their left or right hands. The range of motion is calculated based on how far the player can stretch his hand to the left or the right without changing his location. This value is relatively mapped on to how far the racket can travel in the virtual environment. Whenever the player stretches his hand further, a new maximum value is created, and the rackets inside the virtual environment will reach their limits.

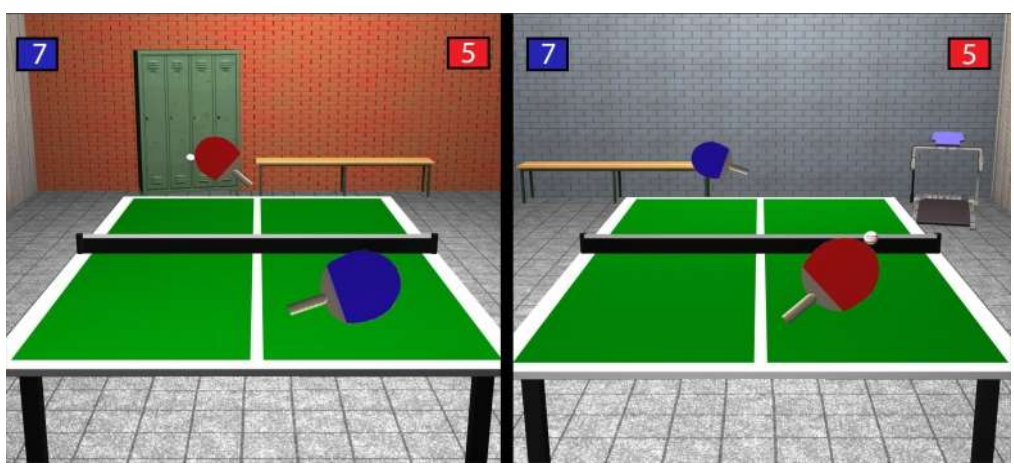

Fig. 1. A screen shot of the table tennis game 


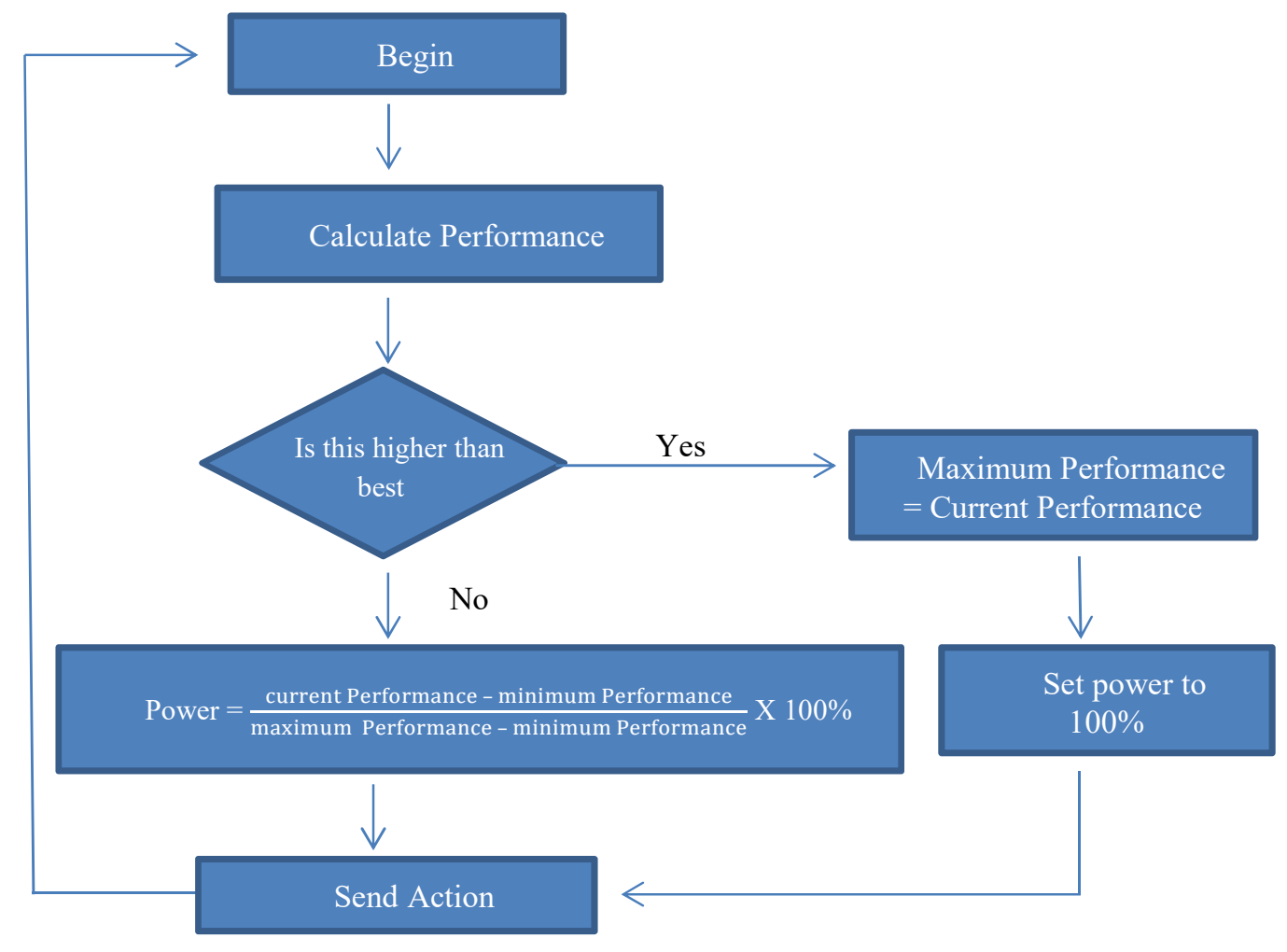

Fig. 2. the Best Hit Algorithm

The values of W1 and W2 are taken from a pre-defined value, which is chosen based on the game context. The values have been set to give certain actions more effects in a specific context. Table 1 shows these pre-set values and the associated game context.

Table 1. pre-defined values for constants $\mathrm{W}_{1}$ and $\mathrm{W}_{2}$ and their gaming context

\begin{tabular}{|l|c|c|}
\hline \multicolumn{1}{|c|}{ Context } & W1 Value & W2 Value \\
\hline Initial Ball Hit & 0.9 & 0.1 \\
\hline Ball Slowing down in the middle & 0.75 & 0.25 \\
\hline Ball Flying outside Table Tennis surface & 0.25 & 0.75 \\
\hline Ball flying fast in the mid area & 0.5 & 0.5 \\
\hline Ball reaches above 90\% its Y limit & 0.4 & 0.6 \\
\hline Ball is deflected on the opposite side of the racket & 0.75 & 0.25 \\
\hline
\end{tabular}




\section{System Evaluation}

To evaluate the system a game playing session was arranged, two groups of participants were recruited, a young participant group, and an older participant group. Two versions of the game are used; version A, with the best-hit algorithm applied, and version B where no algorithm is used. In each round a member of the young group played against a member of the older group, scores and numbers of successful hits were recorded. All of the participants played both versions A and B.

\subsection{Participants}

A group of 5 participants took part in the study and were divided into two groups, an older adult group (1 Male and 2 Females; $\mathrm{M}=84.7$ years, $\mathrm{SD}=2.31$ years), and a younger adult group ( 2 Males, $\mathrm{M}=30$ years, $\mathrm{SD}=2.83$ years). The older participants were recruited from local sheltered accommodation. All of the participants had previous experience playing movement based games. A Timed up and Go test was performed by each participants to evaluate his/her physical capabilities. The test records the time each participant needed to stand up correctly from a sitting position on a chair with arms then walk a distance of three meters, turn and come back and sit correctly in the chair. The mean time taken for the older participants was 13.4 seconds ( $\mathrm{SD}=1.52$ seconds). While the mean time taken for the younger group was $8.7 \mathrm{sec}-$ onds ( $\mathrm{SD}=0.14$ seconds). According to the interpretation of the test a normal person will need less than 10 seconds to perform this test [23]. Table 2 summarizes the all participants' information in the two groups:

Table 2. A Summary of the scores of the TUG test for all participants.

\begin{tabular}{|c|c|c|c|}
\hline Participant code & Age & Gender & $\begin{array}{c}\text { Physical Capability } \\
\text { (Timed up and Go test) }\end{array}$ \\
\hline \multicolumn{4}{|c|}{ Group 1 Older Participants } \\
\hline P1 & 82 & Female & 11.7 second \\
\hline P2 & 86 & Female & 14.7 second \\
\hline P3 & 86 & Male & 13.7 second \\
\hline \multicolumn{4}{|c|}{ Group 2 Younger Participants } \\
\hline P4 & 28 & Male & 8.8 second \\
\hline P5 & 32 & Male & 8.7 second \\
\hline
\end{tabular}

An adequate play space that gives each player enough area to move freely was allocated. The game was projected on a big white screen in front of the players (see Fig.3 which shows the playing area). 


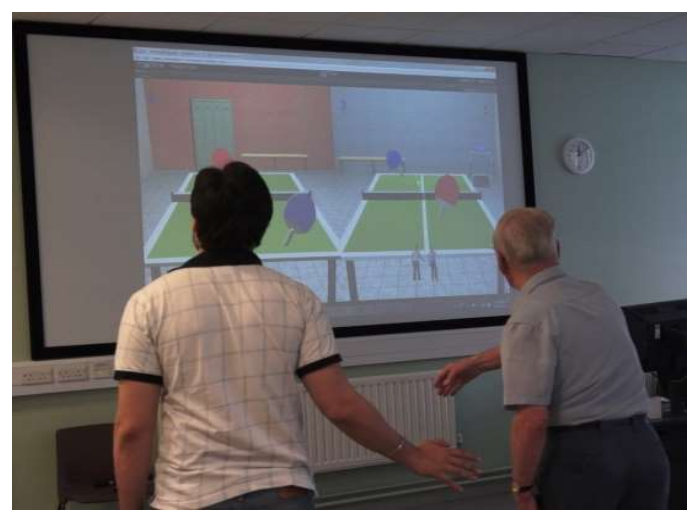

Fig. 3. An example of an older adult playing against a younger adult in the gameplay area.

\subsection{Gaming Sessions}

In total, the game was played ten times, five matches played with the best-hit algorithm implemented, and five without using it. When the algorithm was not being used, the performance measure is based on which player is moving faster. Enabling and disabling the best-hit algorithm was hidden from the players; the algorithm was turned on in one session then turned off in the next. In each match a randomly selected participant from the older group played against a randomly selected player from the younger group. The players were only informed about the use of the algorithm when all playing sessions were completed. Final scores showed that older adults won three sessions out of five when the algorithm is applied, while they lost all five session when it was not as indicated in table 3.

Table 3. gaming sessions final scores

\begin{tabular}{|l|c|c|}
\hline & Older Group & Younger Group \\
\hline With Best hit & 3 & 2 \\
\hline Without Best Hit & 0 & 5 \\
\hline
\end{tabular}

Table 4 shows the detailed score in each match and their duration. Duration was calculated based on the number of total racket hits by both players. In the rounds where the best hit algorithm was applied, the older adult scored a total of 52 points in five matches with an average of 10.4 points per match, compared to the second round when they scored a total of 28 points with an average of 5.6 points per match. The average match duration in the first round was 78.6 racket hits, while in the second round the average duration was 179 racket hits. 
Table 4. A detailed summary of the match results with and without the best-hit algorithm.

\begin{tabular}{|c|c|c|c|}
\hline & Older Group & Younger Group & Match duration \\
\hline \multicolumn{4}{|c|}{ With Best Hit Implemented } \\
\hline & $(\mathrm{P} 1)=13$ & $(\mathrm{P} 4)=7$ & 80 \\
\hline & $(\mathrm{P} 2)=13$ & $(\mathrm{P} 4)=7$ & 59 \\
\hline & $(\mathrm{P} 3)=5$ & $(\mathrm{P} 5)=13$ & 67 \\
\hline & $(\mathrm{P} 1)=13$ & $(\mathrm{P} 5)=8$ & 83 \\
\hline & $(\mathrm{P} 3)=8$ & $(\mathrm{P} 4)=13$ & 104 \\
\hline Total & 52 & 48 & 393 \\
\hline Average & 10.4 & 9.6 & 78.6 \\
\hline \multicolumn{4}{|c|}{ Without Best Hit } \\
\hline & $(\mathrm{P} 2)=3$ & $(\mathrm{P} 4)=13$ & 164 \\
\hline & $(\mathrm{P} 3)=8$ & $(\mathrm{P} 5)=13$ & 261 \\
\hline & $(\mathrm{P} 3)=4$ & $(\mathrm{P} 4)=13$ & 116 \\
\hline & $(P 2)=6$ & $(\mathrm{P} 4)=13$ & 296 \\
\hline & $(P 1)=7$ & $(\mathrm{P} 5)=13$ & 58 \\
\hline Total & 28 & 65 & 895 \\
\hline Average & 5.6 & 13 & 179 \\
\hline
\end{tabular}

\subsection{Performance Profiles}

During each match the performance of both players was tracked. Fig.4 shows the younger adult performance and the older adult performance in one of the matches when the algorithm was not applied, while Fig.5 shows the same performance if the best-hit algorithm is applied. From Fig. 4 we notice that the younger participant outperforms the older participant, while in Fig.5 we notice that their performance is becoming more balanced. We can also notice that the younger participant has reached or exceeded his maximum performance 7 times, while the older adult could do it only once. We notice also that the younger performance deviates more from its mean than the older participant.

There was 41 times where performance was calculated during this match for each participant. The younger performance means and standard deviation are $(\mathrm{M}=6.62$, $\mathrm{SD}=3.56$ ) where the older participant's performance means and standard deviation are $(M=4.69, S D=1.95)$. The assumption of homogeneity of variances was violated, as assessed by Levene's test for equality of variances $(p<.05)$. An examination of the performance values reveals that the results of Mann Whitney U test shows a statistical difference between younger performance and the older performance $(U=574, Z=-$ 
$2.614, \mathrm{p}=0.000<0.05)$ with younger performance mean rank of 49.00 , and older performance rank of 35.17 .

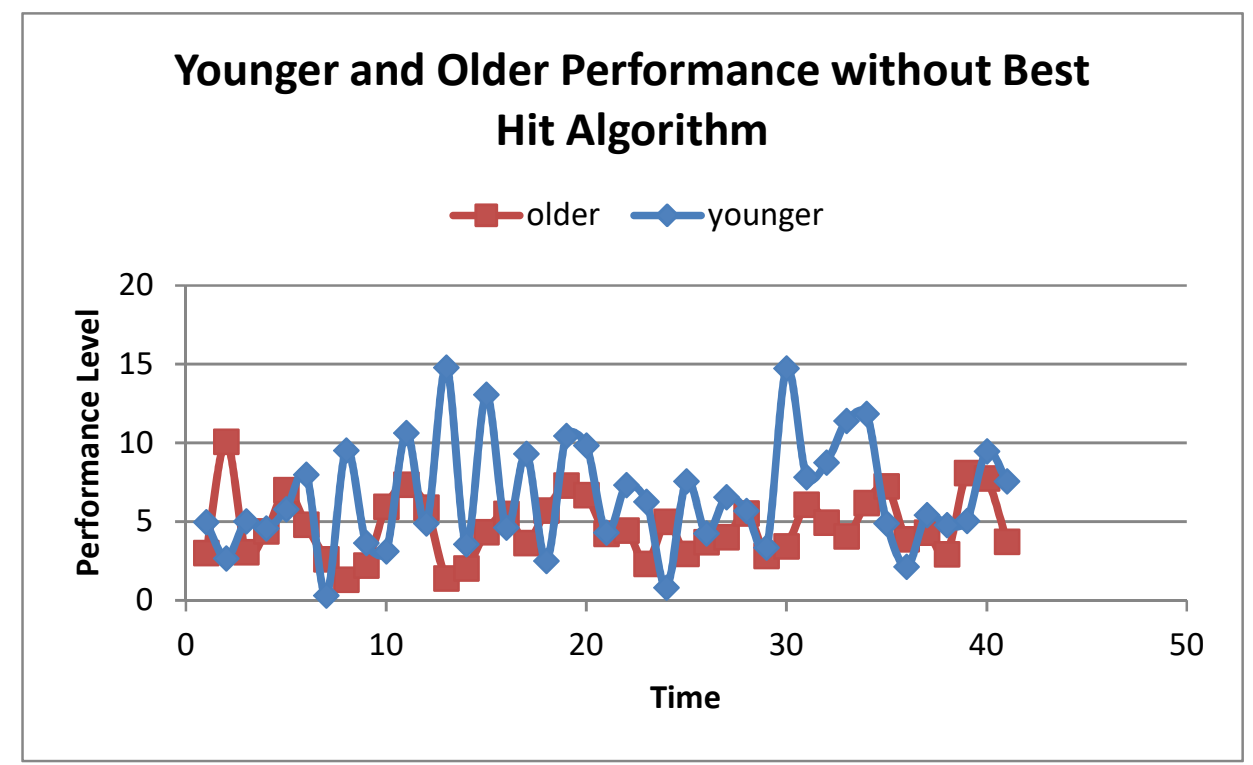

Fig. 4 A graph showing the calculated performance for a younger participant versus an older participant performance over time without using the best-hit algorithm

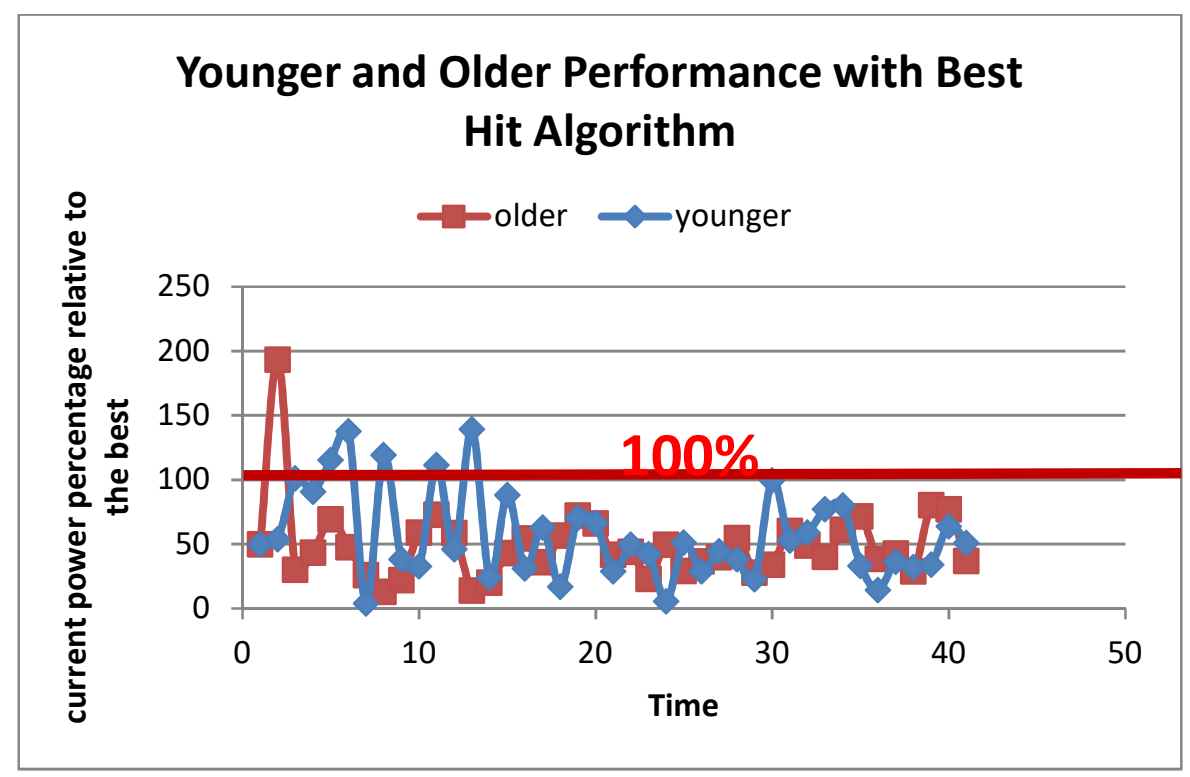

Fig. 5. A graph showing the calculated performance for a younger participant versus an older participant performance over time using the best-hit algorithm 
Another Mann Whitney U test was conducted to determine if the differences in performance between the younger $(\mathrm{M}=57.25, \mathrm{SD}=34.71)$ and the older participants $(\mathrm{M}$ $=49.29, \mathrm{SD}=28.97)$ were significant when the Best Hit Algorithm is applied. Again, the assumption of homogeneity of variances was violated, as assessed by Levene's test for equality of variances $(\mathrm{p}=.048<0.05)$. The test revealed that there was no statistically significant difference in mean performance between older and younger participants when the best-hit algorithm is applied $(Z=-0.886, p=0.376>0.05)$, with younger performance rank of 43.83 and older performance rank of 39.17 .

\section{Discussion}

In the sessions where the best-hit algorithm was used, older adults won 3 out of 5 matches compared to no matches when a standard performance calculation was used. This primary result shows how older adults can be fairly brought into a more evenly competitive field. This is also supported by the number of points scored by both groups in the two matches. For example, the older adults scored 52 points while the younger adults scored only 48 points, suggesting the game was balanced and the competition was high. In the second round, where the best-hit algorithm was not used, the number of points scored by older adults was 28 points while younger adults scored 65 . The competition was not very high and younger adults easily won all the matches.

By analyzing the performance profile of a younger versus an older player before applying the best-hit algorithm we noticed that the performance of a younger adult outperformed that of an older player $(p<0.05)$. When applying the best-hit algorithm we noticed that the performance of the younger players was initially better than the older participant, but as time progressed they became more equal to the older players $(p>0.05)$. Furthermore, the average match duration in the first session was 78.6 hits while in the second one it was 179 hits. A hit is calculated each time a player hits the ball with the racket. We observed a noticeable decline in the number of hits in the rounds when the Best-Hit algorithm is applied. This happened because the players were able to beat their best-hit several times in every match. When this happened the ball is set to the maximum power, which makes it more difficult for the opponent to hit it back. The players beat their best hit because the previous values where calculated only based on the current match. No previous values have been used from other matches for the same player. This scenario made the total time of the match shorter even though the score itself was more competitive. To avoid this scenario the algorithm should be able to track user performance across matches. Another point that needs to be considered is when the average performance becomes very close to the maximum value during game play. In this condition the player can make an average hit that is set very close to the power maximum. To resolve this issue another variable should then be used to track the minimum value, and the average value. 


\section{Conclusions}

In this paper we showed that by applying a Best-Hit algorithm in exergames older adults are more able to compete with the younger players. This appears to increase their levels of engagement and creates a better experience for them. This technique can allow older adults to play more competitively and should allow them to play against their children and grandchildren and still be able to compete. The results from cross-generational gameplay showed that older adults could compete with the younger adults in the movement-based game. Rehabilitation can be converted to a family social activity where older and younger players can play together enjoyable movement-based games. Each member can compete and win regardless of their actual physical ability. Allowing older adults to play with their family members will encourage them to move and exercise more often. This process may open new doors for rehabilitation and re-shape the process by making it a more social activity.

The Best-Hit algorithm still needs more evaluation, it will be beneficial to test the gameplay over a long period of gameplay to see whether the difference of performance between younger player and older will decrease if the older player gains more experience and be more confident with the game.

\section{References}

1. Gerling, K. M., Schulte, F. P., \& Masuch, M. (2011). Designing and evaluating digital games for frail elderly persons. Proceedings of the 8th International Conference on Advances in Computer Entertainment Technology - ACE '11, 1.

2. Jung, Y., Li, W., Gladys, C., \& Lee, K. M. (2009). Games for a Better Life : Effects of Playing Wii Games on the Well-Being of Seniors in a Long-Term Care Facility, 0-5.

3. Vanden Abeele, V., \& De Schutter, B. (2010a). Designing intergenerational play via enactive interaction, competition and acceleration. Personal and Ubiquitous Computing, 14, 425-433.

4. McPherson, A. C., Glazebrook, C., \& Smyth, A. R. (2005). Educational interventions Computers for delivering education to children with respiratory illness and to their parents. Paediatric Respiratory Reviews, 6, 215-226.

5. De Schutter, B., \& Vanden Abeele, V. (2010). Designing meaningful play within the psycho-social context of older adults. In Proceedings of the 3rd International Conference on Fun and Games - Fun and Games '10 (pp. 84-93). New York, New York, USA: ACM Press.

6. Tarling, a. (2005). Older People's Social and Leisure Time, Hobbies and Games.

7. Campbell, T., Ngo, B., \& Fogarty, J. (2008). Game design principles in everyday fitness applications. Proceedings of the 2008 ACM Conference on Computer Supported Cooperative Work, San Diego, 249-252.

8. McElroy, M. (2002). Resistance to exercise: a social analysis of inactivity, 349.

9. Savva, N., \& Bianchi-Berthouze, N. (2012). Automatic recognition of affective body movement in a video game scenario. Lecture Notes of the Institute for Computer Sciences, Social-Informatics and Telecommunications Engineering, 78 LNICST, 149-159.

10. Duh, H. B., Do, E. Y., Billinghurst, M., Quek, F., \& Chen, V. H.-H. (2010). Seniorfriendly technologies: interaction design for senior users. Proceedings of the 28th of the In- 
ternational Conference Extended Abstracts on Human Factors in Computing Systems CHI EA' '10, $4513-4516$.

11. Jaycox, K., \& Bruce, L. H. (1976). Elders, Students and Computers. University of Illinois.

12. Bruner, J. S. (1964). Education as Social Invention. Journal of Social Issues, 20(3), 21-33. Caljouw, S. R., Van Der Kamp, J., \& Savelsbergh, G. J. P. (2006). The impact of taskconstraints on the planning and control of interceptive hitting movements. Neuroscience Letters, 392, 84-89

13. Gamberini, L., Alcaniz, M., Barresi, G., Fabregat, M., Ibanez, F., \& Prontu, L. (2006). Cognition, technology and games for the elderly: An introduction to ELDERGAMES project. PsychNology Journal, 4, 285-308.

14. Consolvo, S., Everitt, K., Smith, I., \& Landay, J. a. (2006). Design requirements for technologies that encourage physical activity. Proceedings of the SIGCHI Conference on $\mathrm{Hu}$ man Factors in Computing Systems - CHI '06, 457-466.

15. Khoo, E. T., Merritt, T., \& Cheok, A. D. (2009). Designing physical and social intergenerational family entertainment. Interacting with Computers, 21, 76-87. doi:10.1016/j.intcom.2008.10.009

16. Kern, D., Stringer, M., Fitzpatrick, G., \& Schmidt, A. (2006). Curball - A prototype tangible game for inter-generational play. Proceedings of the Workshop on Enabling Technologies: Infrastructure for Collaborative Enterprises, WETICE, 412-417.

17. Mahmud, A. Al, Mubin, O., Shahid, S., \& Martens, J. B. (2009). Designing social games for children and older adults: Two related case studies. Entertainment Computing, 1, 147156.

18. Kleinle, K. (2015). How Are Golf Handicaps Calculated? Retrieved March 12, 2015, from http://www.golflink.com/facts_5102_how-golf-handicaps-calculated.html

19. Jansz, J. (2005). Gaming at a LAN event: the social context of playing video games. New Media \& Society, 7, 333-355.

20. De Schutter, B. (2011). Never Too Old to Play: The Appeal of Digital Games to an Older Audience. Games and Culture, 6, 155-170.

21. Jansz, J., \& Tanis, M. (2007). Appeal of playing online First Person Shooter Games. $C y$ berpsychology \& Behavior: The Impact of the Internet, Multimedia and Virtual Reality on Behavior and Society, 10, 133-136.

22. Caljouw, S. R., Van Der Kamp, J., \& Savelsbergh, G. J. P. (2006). The impact of taskconstraints on the planning and control of interceptive hitting movements. Neuroscience Letters, 392, 84-89. Podsiadlo, D., \& Richardson, S. (1991). The Time "Up \& Go": A Test of Basic Functional Mobility for Frail Elderly Persons. Journal of the American Geriatrics Society, 39(2), 142148. 